U N I DADE DE IN VESTIGAÇÃ O (U ICISA-E)

\title{
Second European Meeting of the Joanna Briggs Institute Collaboration
}

Portugal Centre for Evidence Based Practice (PCEBP):

an Affiliate Centre of the Joanna Briggs Institute

\section{NEWSLETTER}

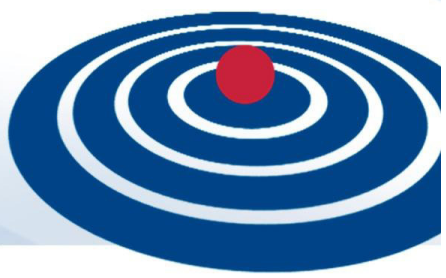

\section{Março 2013}

O Portugal Centre for Evidence Based Practice (PCEBP) é um Centro Afiliado JBI, acolhido pela Unidade de Investigação em Ciências da Saúde Enfermagem (UICISA-E), da Escola Superior de Enfermagem de Coimbra (ESEnfC). Este ano o PCEBP está a organizar o $2^{\circ}$ Encontro Europeu Anual do Joanna Briggs Institute.

Web Site JBI: http://www.joannabriggs.edu.au/ Web Site do PCEBP: http://www.esenfc.pt/site/?mo dule $=$ ui\&target $=$ page $\& i d=11665$
O $2^{\circ}$ Encontro Europeu Anual do Joanna Briggs Institute, além do período de tempo dedicado ao trabalho específico dos membros e diretores dos centros colaboradores europeus, irá integrar um simpósio aberto com a finalidade de divulgar em Portugal a ação dos centros JBI e discutir problemáticas atuais muito relevantes para a prática baseada na evidência, almejando ganhos significativos em saúde.

Para ver o programa e registar-se por favor visite 0 website do evento em: http://www.esenfc.pt/event/ event/home/index.php?target $=$ home\&defLang $=$ 1 \&event $=112$

Organizado por Daniela Filipa Batista Cardoso (Licenciada em Enfermagem, Bolseira de Investigação na UICISA-E no projeto Portugal Centre for Evidence Based Practice: an Affiliate Centre of the Joanna Briggs Institute)

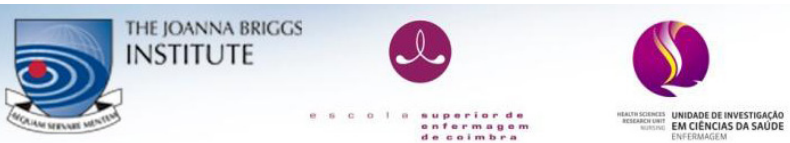

Revista de Enfermagem Referência $\mid$ III Série - n. 9 9-Abr. 2013 
